\title{
Colony Structure of the Weaver Ant, Oecophylla smaragdina (Fabricius) (Hymenoptera: Formicidae)
}

by

\author{
Marcela, P. a , Abu Hassan, A. ${ }^{a}$, Nurita, A.T. ${ }^{\text {a }}$ \& Kumara Thevan ${ }^{\mathrm{b}}$
}

\begin{abstract}
The colony structure of Oecophylla smaragdina within the compound of UniversitiSains Malaysia, PenangIsland, Malaysia was determined. The current study involved a total of twelve nests which were taken from two different locations. Each nest was dissected and the specimens were separated according to their caste. Results show that the colony structure of $O$. smaragdina consisted of a dealate queen, eggs, larvae of female alates, pupae of major and minor workers, pupae of female alates, major workers, minor workers, female alates and male alates. Our present study shows that $O$. smaragdina had a distinct caste system and the numbers of individuals in each caste reflect their respective functions which contributed to the success of their colony.
\end{abstract}

Keywords: Oecophylla smaragdina; nests; caste; colony structure

\section{INTRODUCTION}

Weaver ants, or Oecophylla, are eusocial insects of the family Formicidae (Order: Hymenoptera). They are classified under the subfamily Formicinae. Weaver ants are obligate arboreal species and are known for their unique nest building behavior where workers construct nests by weaving together leaves using larval silk (Hölldobler \& Wilson 1990). The Asian weaver ant, $O$. smaragdina is well distributed throughout most of the Oriental region from India to Queensland and the Solomon Island (Greenslade 1972). They are also common in the lowland of Peninsular Malaysia and have become an important ant in the tree canopies of the humid tropics of Southeast Malaysia, Australia, and Pacific islands (Jander \& Jander 1979; Bluthgen \& Fiedler 2002).

Previous studies reported the existence of single or multiple queens in the colonies of O. smaragdina (Greenslade 1971; Peeters \& Andersen 1989;

\footnotetext{
aSchool of Biological Sciences, Universiti Sains Malaysia, 11800 Penang, Malaysia.

${ }^{b}$ Department of Forensic Medicine, Penang Hospital, 10990 Residensi Road, Penang, Malaysia. Corresponding author email: aahassan@usm.my
} 
Hölldobler \& Wilson 1983; 1990). However, little was known about the colony composition and caste system such as the existence of reproductive individuals and non-reproductive individuals of these weaver ants. Despite being well-studied for other biological attributes, the colony structure of $O$. smaragdina has received less attention (Schlüns et al.2009). Studies on colony structure and caste composition might be able to explain how the social structure inside the nest influence the behaviour of individuals outside the nest. Therefore, the objective of the current study was to report the colony structure of $O$. smaragdina inside the nests of this species.

\section{MATERIALS AND METHODS}

This study was conducted in November 2010 until February 2011 at the main campus of Universiti Sains Malaysia, Penang Island, Malaysia. Two colonies of weaver ants, located $500 \mathrm{~m}$ from each other, were chosen for this study. The boundary of each colony was determined by following the ant trails. The first colony was located behind the "Kelas Al-Quran dan Fardu Ain" building (KAFA) and the second colony was located near the building of the School of Industrial Technology (TI). The KAFA colony made nests on five mango trees (Mangifera indica) whereas the TI colony made nests in a "mempari" tree (Millettia pinnata). Total nests sampled were twelve, where eight nests taken from the KAFA colony and four nests from the TI colony. These nests were removed from the trees by cutting the base of the nest using a long cutter (Sharpex) and placing it into plastic buckets $(60 \mathrm{~cm} \times 80 \mathrm{~cm})$ containing cotton wads wetted with chloroform.

All nests were collected in between 10 a.m. to 12 p.m., corresponding to the time of day when the weaver ants were least active which was determined in a preliminary study. Each nest was kept separately in individual plastic buckets. These plastic buckets were brought back to the laboratory and kept inside a fume hood for 24 hours to ensure that the weaver ants were all dead. After 24 hours, the nests of $O$. smaragdina ants were dissected and sorted according to the following castes: dealate queens, egg, larvae, pupae, female alates, male alates, major workers and minor workers. The number of individuals of each caste for each nest were counted and recorded. The collected specimens were preserved in $95 \%$ ethanol. The images of each specimen of $O$. smaragdina were 


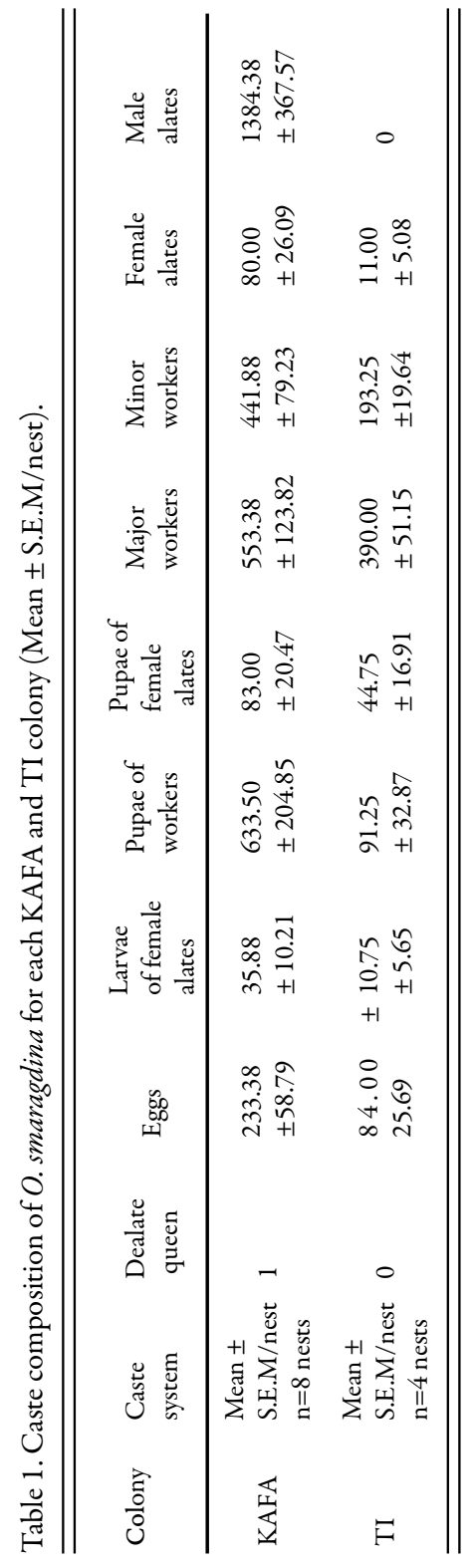

captured and $s$ measurements were determined using a stereomicroscope (Olympus SZX9) which was connected to Image analyser Cell A (Dell Inc. computer). The mean number and standard error of mean (S.E.M) for each caste was determined using Statistical Packages for the Social Sciences (SPSS 11.5).

\section{RESULTS}

Table 1 shows the caste composition of $O$. smaragdina from the twelve nests sampled. One dealate queen was found in the KAFA colony (Fig. 1). The dealate queen of $O$. smaragdina found in the field was green to brown in color. In contrast, the male alates of $O$. smaragdina were black in color and smaller in size (Fig. 2). The female alates of the KAFA colony were green in color with unshed wings (Fig. 3). However, the female alates of the TI colony were yellow in color with unshed wings (Fig. 4). The major workers were bigger in size compared to minor workers (Fig. 5; Fig. 6). Table 1 also shows that the highest number in any individual caste was male alates in the KAFA colony $(1384.38 \pm 367.57)$, however no male alates were observed in the TI colony. In addition, the number of major workers was higher than the minor workers for both colonies (KAFA $=553.38$ \pm 123.82; $441.88 \pm 79.23)(\mathrm{TI}=390.00$ $\pm 51.15 ; 193.25 \pm 19.64)$. Both eggs and larvae were white in color and similar in 
shape but the larvae were bigger in size (Fig. 7; Fig. 8; Fig. 9). The pupae had developed eyes, mouth, legs and wings that were very similar to the adults (Fig. 10; Fig. 11; Fig. 12).
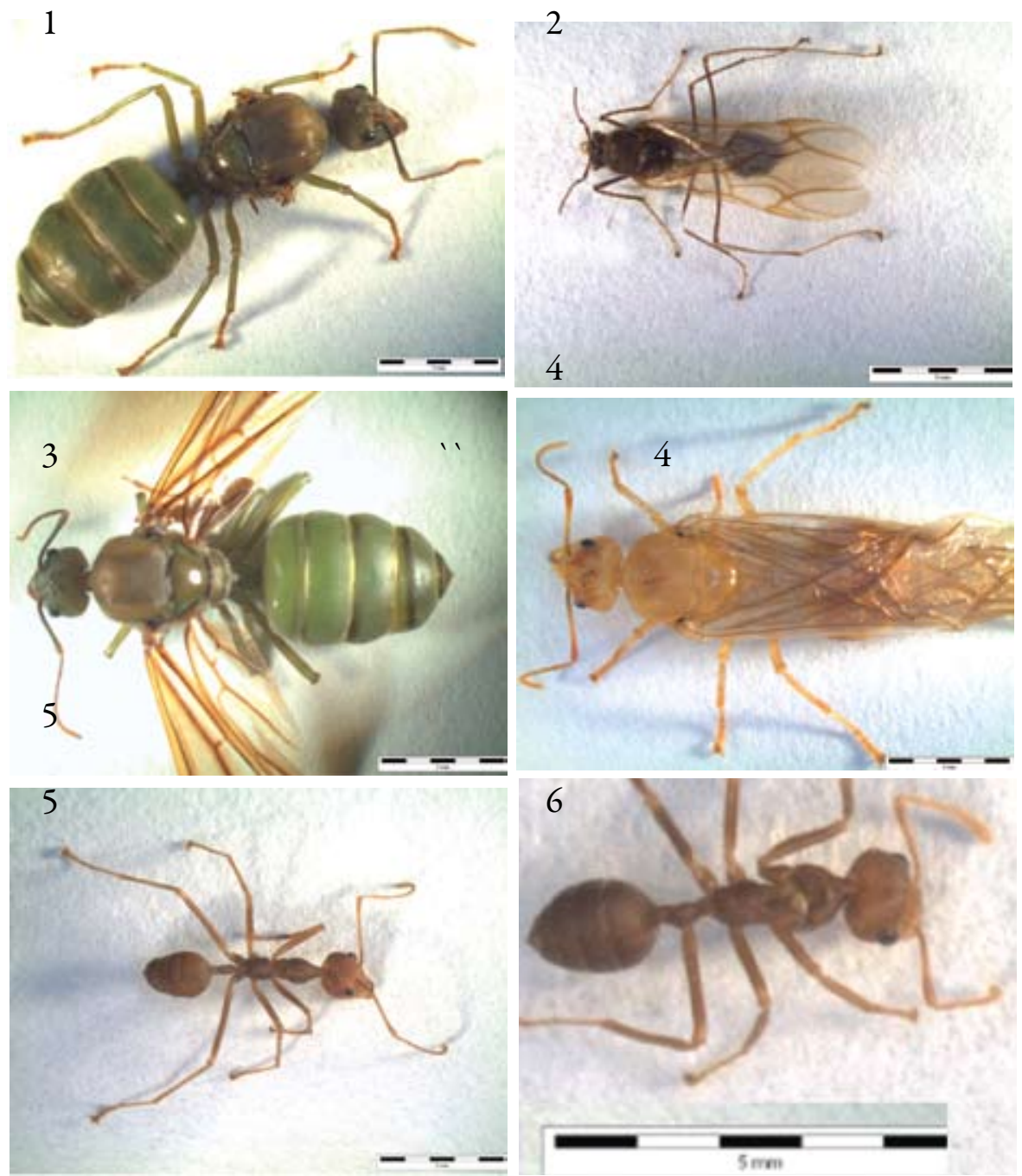

Figs. 1-6: Fig. 1.Dealate queen of $O$. smaragdina from KAFA colony; Fig. 2. Male alate of $O$. smaragdina from KAFA colony; Fig. 3. Female alate of $O$. smaragdina from KAFA colony; Fig. 4. Female alate of $O$. smaragdina from TI colony; Fig. 5. Major worker of $O$. smaragdina from both colonies; Fig. 6 . Minor worker of $O$. smaragdina from both colonies. 


\section{DISCUSSION}

The current study showed the basic colony structure of $O$. smaragdina ants consisted of dealate queens, male alates, female alates, major workers, minor workers, eggs, larvae and pupae. This result corresponded to Lee et al. (2003)
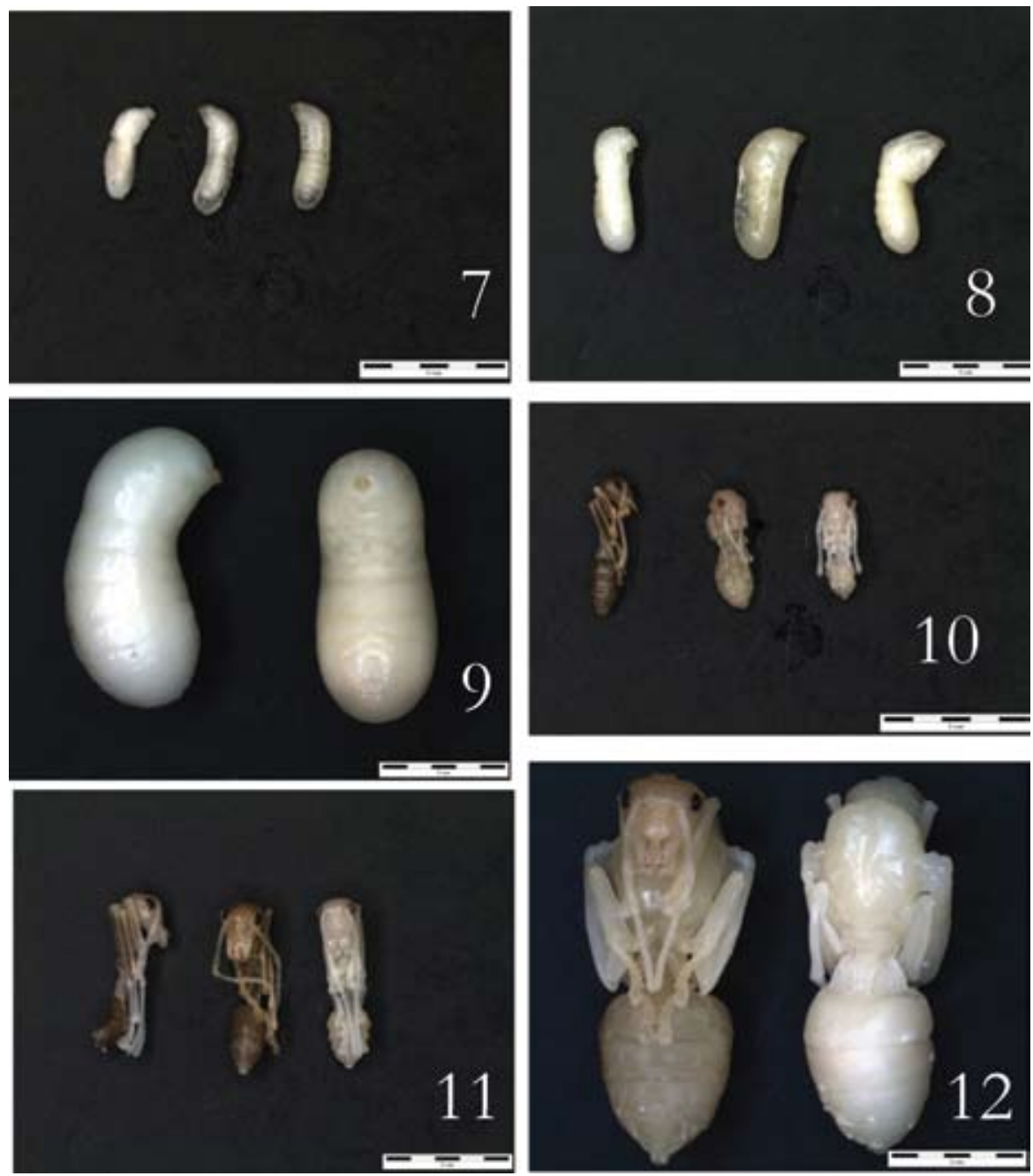

Figs. 7-12: Fig. 7. Eggs of minor worker of $O$. smaragdina from both colonies; Fig. 8. Eggs of major worker of $O$. smaragdina from both colonies; Fig. 9. Larvae of female alate of $O$. smaragdina from both colonies; Fig. 10. Pupae of minor workers of $O$. smaragdina from both colonies; Fig. 11 . Pupae of major workers of $O$. smaragdina from both colonies; Fig. 12. Pupae of female alate of $O$. smaragdina from both colonies. 
where the $O$. smaragdina ants had a complete metamorphosis consisting of immature stages (eggs, larvae, and pupae) and adults with reproductive stage (dealate queen) and non-reproductive stage (workers). The workers of $O$. smaragdina were all females and had a dimorphism or bimodal size-frequency distribution known as major and minor workers (Wilson 1953; Greenslade 1972; Hölldobler \& Wilson 1990).The specific function of each individual adult in a colony is determined by the existence of the caste system and this division of labour is important for the continuous survival of the colony (Lee et al. 2003). Contrary to the current study, Peng et al. (1998a; 1998b) reported that there were large numbers of major workers, eggs, early-instar larvae and some minor workers within each queen nest, but no pupae or medium-sized or large-sized larvae. Way (1963) also reported that the brood (immature stages) of $O$. smaragdina is not raised in 'pavilions'; the pavilions are constructed in the same way as nests where many homopterans are tended by ants, often several meters away from the nearest ant nest.

Only one dealate queen found in the KAFA colony and no dealate queen was found in the TI colony. This may be due to the KAFA colony was established much earlier than the TI colony. The nests which were taken from the TI colony were also fewer in numbers and smaller in size compared to the nests of the KAFA colony. Similar to the present study, Peng et al. (1998b) reported that young mango trees which were closer to the matured mango trees with well-established O. smaragdina colonies were found to have more dealate queen nests. After being inseminated by a male ant during nuptial flight, the winged queen shed her wing (Oster \& Wilson 1978; Lokkers 1990). The queen would then begin to construct the first nest cell and rears its first brood of workers. Soon, the workers would take over the tasks of foraging and brood care, allowing the queen to confine herself to egg-laying (Oster and Wilson 1978). Therefore, the presence of a dealate queen in the KAFA colony showed that the colony was well-maintained compared to the TI colony.

The number of male alates in the KAFA colony was higher than the female alates might be due to the female alates could mate with more than one male during swarming $(1384.38 \pm 367.57 ; 80.00 \pm 26.09)$. This result was supported by Schlüns et al. (2009) who reported that direct genotyping of the sperm carried by 77 Queensland queens and worker genotypic arrays of 
established colonies of $O$. smaragdina showed that less than half of the queens mate only once, while some mate up to five times, which suggested that more males were involved during mating than the females. Similar behavior was also observed in Formica subpolita ants where the females controlled who they mated with and were observed to mate with up to 4 different males, before dispersing from swarm sites (O’Neill 1994). Female ants may mate just once, but multiple mating is apparently typical for many species (Hölldobler \& Wilson 1990). Lee et al. (2003) explained that male ants have only one task, which is to inseminate the queen. They usually possess wings and mating can occur within the nest or outside the nest (swarming). Shortly after mating, the males die and the queens settle and establish new colonies (Schlüns et al. 2009; Lee et al. 2003).

For the female alates found inside the nests, the yellow color was also observed in the study of intercolony transplantation of $O$. smaragdina by Krag et al. (2010). They reported that the O. smaragdina can be categorized into the following distinct groups: larvae, pupae, light yellow callow workers and red mature workers. Lee et al. (2003) explained that a newly hatched adult which has not yet acquired its deep coloration is known as a callow. It will undergo coloration as it grows older. Therefore, it could be that the yellow colored female alates of the TI colony were newly emerged adults that had not yet acquired its deep coloration (callow) (Fig. 4). This result supported that the KAFA colony was established much earlier than the TI colony due to the presence of the matured female alates with greenish color in the KAFA colony. Our results also show that the number of female alates in the KAFA colony was higher than the TI colony $(80.00 \pm 26.09 ; 11.00 \pm 5.08)$.

Thehigher number of major workers compared to minor workers discovered in the current study could be due to task allocation. The major workers have more tasks than the minor workers do and therefore more major workers would be needed (Lee et al. 2003). This result corresponds to previous studies which demonstrated that the major workers do virtually all of the foraging, defend the colony, care for the queen and assist in the care of the brood (Chapuisat and Keller, 2002), whereas the minor workers mostly remain inside the leaf nests and function as nurses of the brood studies (Hölldobler \& Wilson 1978; 1990). This allocation of tasks to different castes of O. smaragdina creates an efficient society (Saarinen 2006). 
The eggs were small and ellipse-shaped with a size around $0.5 \mathrm{~mm} \times 1.0 \mathrm{~mm}$. The eyes and mouth of the larvae within the eggs could be seen when they were observed under a magnifying glass. The pupae could be differentiated from the mature adults because they were white in color (Van Mele \& Cuc 2007). The $O$. smaragdina colonies could produce a large number of "queen brood" every year. The "queen brood" refers to larvae and pupae, which are destined to become new queens as well as their last stage as imago virgin queens (Cesard 2004; Offenberg \& Wiwatwitaya 2010). The current study also showed that $O$. smaragdina ants built new nests within 14 days after their nests were taken. The new nests were located near to the nests which were taken for our study. Regarding this condition, Paimin and Paimin (2001) reported that under normal conditions, weaver ants have a quick population recovery with regeneration time between 17 and 24 days. Others reported it takes five days before new nests appear and around 20 days for the ants to produce new larvae (Cesard 2004).

A caste can be characterized as a set of individuals in a colony, morphologically distinct from other individuals and specialized in behavior which performs specialized task in the colony (Oster \& Wilson 1978). The present study showed that different caste of $O$. smaragdina ants performed different but specific task to maintain their colony well. Hölldobler \& Wilson (1990) stated a colony which is large enough to produce new, virgin queens known as "mature colony" and the efficiency of the mature colony is determined by the number of workers in each temporal caste at any given moment. This suggests that the KAFA colony in the current study was a mature colony of $O$. smaragdina with the presence of a dealate queen and more workers compared to the TI colony.

\section{ACKNOWLEDGMENTS}

The authors thank the Dean of the School of Biological Sciences, Universiti Sains Malaysia for the facilities and funding provided for the research.

\section{REFERENCES}

Blüthgen, N. \& K. Fiedler. 2002. Interactions between weaver ants, Oecophylla smaragdina, homopterans, trees and lianas in an Australian rainforest canopy. J. Anim. Ecol. 71: 793-801. 
Cesard, N. 2004. Harvesting and commercialization of kroto (Oecophylla smaragdina) in the Malingping area, West Java, Indonesia, pp. 61-77. In: 1-Aisa., K. Kusters \& B. Belcher (eds). Forest Products, Livelihoods and Conservation. Case studies of Non-Timber Forest Product Systems. Center for International Forestry Research. Jakarta.

Chapuisat, M. \& L. Keller. 2002. Division of labour influences the rate of ageing in weaver ant workers. Proc. Biol. Sci. 269: 909-913.

Greenslade, P.J.M. 1971. Phenonology of three ant species in Solomon Islands. J. Aust. Entomol. Soc. 10: 241-252.

Greenslade, P. J. M. 1972. Comparative ecology of four tropical ant species. InsectesSociaux 19: 195-212.

Hölldobler, B. \& E.O. Wilson. 1978. The multiple recruitment systems of the African weaver ant, Oecophylla longinoda (Latreille) (Hymenoptera: Formicidae). Behav. Ecol. Sociobiol. 3: 19-60.

Hölldobler, B. \& E.O. Wilson. 1983. Queen control in colonies of weaver ants (Hymenoptera: Formicidae). Ann. Entomol. Soc. Am. 76: 235-238.

Hölldobler, B. \& E.O. Wilson. 1990. The Ants. Belknap Press of Harvard University Press, Cambridge, MA. 732 pp.

Jander, R. \& U. Jander. 1979. An exact field test for the fade-out time of the odour trails of the Asian weaver ants, Oecophylla smaragdina. Insectes Sociaux 26: 165-169.

Krag, K., R. Lundegaard, J. Offenberg, M.G. Nielsen \& D. Wiwatwittaya. 2010. Intercolony

transplantation of Oecophylla smaragdina (Hymenoptera: Formicidae) larvae. J. Asia Pac. Entomol. 13: 97-100.

Lee, C.Y., J.Zairi,H.H. Yap \&N.L. Chong. 2003. Urban Pest Control-A Malaysian Perspective, 2nd Edition. pp. 71-74. Universiti Sains Malaysia, Penang, Malaysia.

Lokkers, C. 1990. Colony dynamics of the Green Tree Ant, (Oecophylla smaragdina Fab) in a seasonal tropical climate. Ph.D. thesis. James Cook University of North Queensland. $322 \mathrm{pp}$.

Offenberg, J. \& D. Wiwatwitaya. 2010. Sustainable weaver ant (Oecophylla smaragdina) farming: Harvest yields and effects on worker ant density. Asian Myrmecology 3: $55-62$.

Neill, K.M. 1994. The male mating strategy of the ant, Formica subpolita Mayr (Hymenoptera: Formicidae): Swarming, mating and predation risk. Psyche 101: 93-108.

Oster, G.F. \& E.O. Wilson. 1978. Caste and ecology in social insects. Princeton University Press, Princeton, New Jersey. 352 pp.

Paimin, F.B. \& F.R. Paimin. 2001. Budi daya semut rangrang penghasil kroto [Élevage de la fourmi rangrang productrice de kroto]. Penebar Swadaya, Jakarta.

Peng R., K. Christian \& K. Gibb. 1998a. Locating queen ant nests in the green ant, Oecophylla smaragdina (Hymenoptera, Formicidae). Insectes Sociaux 45: 477-480.

Peng R., K. Christian \& K. Gibb. 1998b. How many queens are there in mature colonies of the green ant, Oecophylla smaragdina (Fabricius). Aust. J. Entomol. 37: 249-253. 
Peeters, C. \& A. Anderson. 1989. Cooperation between dealate queens during colony foundation in the green tree ant, Oecophylla smaragdina. Psyche 96: 39-44.

Saarinen, E.V. 2006. Differences in worker caste behaviour of Oecophylla smaragdina (Hymenoptera: Formicidae) in response to larvae of Anthene emolus (Lepidoptera: Lycaenidae). Biol. J. Linn. Soc. 88: 391-395.

Schlüns, E.A., B.J. Wegener, H. Schlüns, N. Azuma, K.A. Robson \& R.H. Crozier. 2009. Breeding system, colony and population structure in the weaver ant, Oecophylla smaragdina. Mol. Ecol. 18: 156-167.

Van Mele, P. \& N.T.T. Cuc. 2007. Ants as friends: Improving your tree crops with Weaver ants. (2nd Edition). Africa Rice Center (WARDA), Cotonou, Benin and CABI, Egham, UK. 72 pp.

Way, M.J. 1963. Mutualism between ants and honeydew-producing Homoptera. Annu. Rev. Entomol. 8: 307-344.

Wilson, E.O. 1953. The origin and evolution of polymorphism in ants. Q. Rev. Biol. 28: 136-156. 